"This is a preprint of the following chapter: Lima, F., Burrows, A., Lemos, L., Lucena, P., Pessoa, R., José, R. \& Trigueiros, P., An industry-academia, multidisciplinary and expertise- heterogeneous design approach: A case study on designing for mobility, published in Advances in Design and Digital Communication II, edited by N. Martins and D. Brandão (Eds.), 2022, Springer reproduced with permission of Springer Nature Switzerland AG 2022. The final authenticated version is available online at: http://dx.doi.org/10.1007/978-3-030-89735-2".

Version of Record available at: https://link.springer.com/chapter/10.1007/978-3-030-89735-2_23

\title{
An industry-academia, multidisciplinary and expertise- heterogeneous design approach: A case study on designing for mobility
}

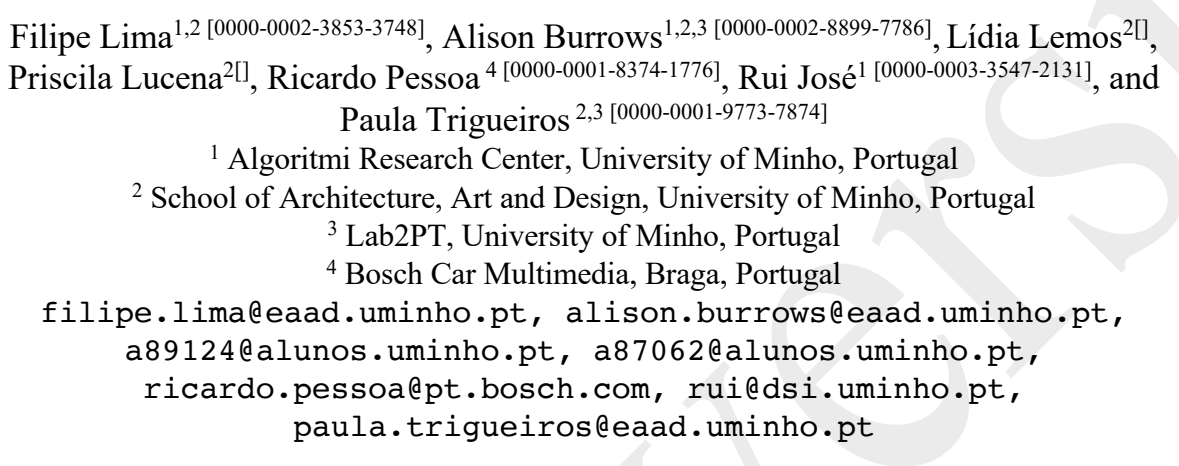

\begin{abstract}
The purpose of this article is to provide a better understanding of how to effectively develop design projects that simultaneously leverage industry and academic partners, participants from various disciplinary backgrounds, and various levels of expertise to solve complex problems. The article reports a single case of an ongoing project focused on designing smart and connected devices for mobility, which integrates the dimensions of interest. Our findings highlight the importance of careful planning of the collaborative process, contemplating offline and real-time communication opportunities, identifying cross-boundary roles, and considering the development of shared expertise and knowledge within the team. By confronting these findings with key literature, we offer five recommendations to inform similar future projects.
\end{abstract}

Keywords: Design, Boundary Crossing, Complex Problems, Innovation, Project Coordination.

\section{Introduction}

The nature of the open socio-technical problems [1] being tackled by institutions in society requires alternative working models that go beyond single actors and siloed monodisciplinary approaches. Different literature streams advance specific alternative models, yet they are still explored in a fragmented and dispersed way, revealing a need for further integration and synthesis. Advocates of the Open innovation paradigm [2] argue that inter-organization collaborations leverage distributed knowledge that together can contribute to the co-production of new innovative solutions for existing 
problems. Here, Industry-Academia Collaborations (IACs) emerge as one particular mode of collaboration that brings its own set of challenges and opportunities [3]. The use of multidisciplinary approaches is also conceived as a way to discover novel ways of tackling complex problems, which would not be accessible with monodisciplinary approaches [4,5]. Additionally, it is acknowledged that individuals with different levels of expertise [6] in design might perform differently when being assigned to specific activities [7]. In certain work settings, teams promoting interactions between individuals with different levels of expertise might enable the creation of new knowledge that can be instrumental for solution generation and evaluation [8]. In light of those observations, Industry-Academia Collaborations, multidisciplinarity and expertise-heterogeneous teams present alternative working modalities to support organizations in tackling contemporary problems. This work lies at the intersection of those three modalities of work, and aims to provide an understanding on how to effectively develop design-led projects that simultaneously involve industry and academic partners, participants from various disciplinary backgrounds, and with various levels of expertise to solve complex problems. It therefore responds to recent calls to systematize and boost the potential of IACs [9] and to explore the transference, multidisciplinary, and collaborative approaches [10].

In its aim, the project reported herein addresses a problem that can be described as 'wicked' $[1,11]$. Urban cycling is an inherently complex activity that occurs in a dynamic context, socially negotiated amongst other road or path users such as automotive drivers, other cyclists, and pedestrians. When combined with the search for smart technological solutions capable of facilitating or enhancing the cycling experience, this challenge becomes even more nuanced and multi-layered. As with any wicked problem, the focus of this project was subject to redefinition and resolution in different ways over time, it was to some extent subjective rather than objectively given, any possible solution has no ultimate test of validity, and any testing of solutions should take place in a real-life setting [12]. With this in mind, the project team was assembled not because of an arguably elusive shared understanding of design, its underlying assumptions and pathways to implementation, or because it possessed an agreed approach and methodology [11]. Rather, the project necessitated a purposely heterogeneous team, in three core respects. First, it brought together industry and academia capabilities in the form of an established technology development organization and a university. Second, it combined individuals from diverse engineering and design backgrounds. Third, it leveraged novice-expert interactions through the inclusion of individuals at differing levels in their career. The research team was therefore uniquely placed to critically observe the development of the project and gather data on its effectiveness.

This paper makes two main contributions for extant design literature. It integrates different research streams on design, computer sciences, management science, knowledge management to provide a more robust understanding of how to conduct projects that simultaneously enable the collaboration between industry and academia, across disciplines, and involving different levels of expertise. Additionally, it provides an inside view of an ongoing short-term design-led project and details how this informed recommendations for conducting similar projects. The rest of the paper comprises four additional sections. In the following section, relevant literature is reviewed 
according to three core themes of this paper: industry-academia collaborations, knowledge diversity, and levels of experience and expertise. In the third section, we describe our work approach, providing detail about the team composition, how collaboration was established and sustained in light of the restrictions created by the Covid19 pandemic, and the design process implemented. In the fourth section, discussion of our experiences and findings in the context of relevant literature helped uncover five recommendations that we propose for similar projects in the future. Finally, we conclude the paper by summarizing its main content and identifying avenues for further work.

\section{Related work}

\subsection{Academia and industry}

Designing effective technology is a dynamic and unpredictable pursuit, predicated on complex socio-technical factors and ultimately validated by market acceptance. To this end, the Open Innovation paradigm advocates inter-organization collaboration as a pathway to technological advancement, incorporating internal as well as external ideas into sustainable business models [2]. Open Innovation therefore thrives on an abundance of knowledge that is freely transferred between the various institutional actors involved, who in turn contribute to the co-production of more competitive products and services [10]. One renowned example of inter-organization partnerships in this domain are Industry-Academia Collaborations (IACs), which have recently been analysed at length [9]. IACs are the cornerstone of contemporary applied research and development, often being an indicator of potential real-world impact and a requirement for obtaining funding. Nevertheless, implementing IACs in practice produces varying results, which can be explained at least in part by understanding the boundary between an organization and external actors as a semipermeable membrane [3]. This means knowledge flows through it to varying degrees and at different rates. This is conceptualized in the model proposed by Wohlin [13], which contemplates five levels of closeness between industry and academia. In the first three levels of this model - named 'Not in touch', 'Hearsay', and 'Sales pitch' - the link between industry and academia is nonexistent or extremely tenuous. It can therefore be argued that true IACs only take place at levels 4 and 5, where a two-way connection occurs between industry and academia with a view to collaboratively identifying a problem and working towards a solution ('Offline' at level 4 and as 'One team' at level 5).

A considerable amount of work has gone into identifying barriers to successful IACs, as well as advancing best practices to address them. While it is beyond the scope of this paper to delve too deeply into these topics, we refer to the work of Garousi et al. [14] for a comprehensive analysis of this literature. In brief, those authors identified ten categories of challenges. The largest of these categories, labelled 'mismatch between industry and academia', includes differences in objectives (citing [15-17]), reward systems (citing [18-20]), and time horizons. Garousi et al. [14] observe that the latter may constitute the most common challenge, as it was mentioned in over a quarter of all 
studies surveyed. Importantly, challenges and best practices are interconnected, therefore early awareness of potential IAC challenges is crucial for planning and risk management of such projects. Although progress has been slow to date, it has been noted that it is timely to take advantage of strong bilateral enthusiasm to systematize and increase efforts towards fruitful industry-academia collaborations [9].

\subsection{Leveraging knowledge diversity}

Innovation is likewise boosted by the availability of and recourse to diverse knowledge. Indeed, combining various areas of expertise may help uncover novel ways of solving complex problems that would not be possible if a more domain-specific approach were taken $[4,5]$. Such collective creativity [21] tends to occur by combining disciplines or knowledge domains, conceptualized as three distinct but related approaches. From least to most integrated, these are: multidisciplinarity, where collaboration occurs between disciplines but disciplinary boundaries are not crossed; interdisciplinarity, where some cross-pollination occurs between disciplines working towards a coordinated and coherent goal; and transdisciplinarity, where disciplines fully merge amongst themselves. For a current and comprehensive discussion of these terms, we recommend the work of Moirano et al. [22]. Those authors argue that collaboration across disciplines is also integral to the development of learners in an educational context, who gain substantially in cognitive functions such as originality, fluency and flexibility, and problem-solving skills in real-world settings. However, despite their compelling and multi-layered benefits, any type of collaboration involving various disciplines is not without challenges. Ironically, the knowledge diversity that can be harnessed as a vehicle for creativity and innovation may also act as a barrier to such processes [23].

Here, as with the IACs discussed above, it is worth considering the literature on boundaries in order to identify a possible way forward. We begin by summarizing the three principal types of knowledge boundary, as described in [24]. A syntactic knowledge boundary happens when there is no shared syntax, thus fostering concern that information is not properly processed across a given boundary. A semantic knowledge boundary happens when, even though there is a common syntax, differing interpretations of the common syntax make communication and collaboration difficult. Pragmatic knowledge boundary happens when actors are resistant to transforming their existing knowledge and skills to achieve a common goal. The concepts of boundary crossing objects $[25,26]$ and individuals [27] have been explored as ways to negotiate these knowledge boundaries. These constitute artifacts or people that are flexible enough to allow different groups to work together without consensus, but also robust enough to maintain a common identity across different contexts [26]. Boundary objects need not be tangible and may include figures of speech or renaming a concrete phenomenon in a metaphorical manner, especially in the sharing of tacit knowledge and understanding between people [28]. More recently, it has been noted that a design approach itself can serve as an interactive boundary object, as it facilitates interactions across disciplines [29]. 


\subsection{From novices to experts}

Individuals have different levels of proficiency in applying their skills and the implications of progressing from lower to higher levels through practical experience or education are well known. Notably, Dreyfus and Dreyfus [6] propose that, during the development of a skill, individuals go through five levels (novice, advanced beginner, competent, proficient, and expert) and operate differently. Those differences include that more skilled individuals might change from relying on abstract principles to their concrete experience, or that they might shift their understanding of a situation from a compilation of equally relevant parts to a whole in which only certain parts are essential. The Dreyfus Model of general skills development is originally grounded on studies of chess players, army tank drivers, air force pilots and commanders [6, 30,31], although later studies expand the focus and considerations to healthcare professionals such as nurses [32], educators [33] and others. Based on an understanding of how expertise is built, studies derive specific implications for instruction to facilitate a successful progression [34].

The design research community also makes specific efforts to depict the nature of design expertise $[35,36]$ and to provide a better understanding of the differences between novices and experts in design. While adopting the Dreyfus Model as a theoretical basis to better appreciate the development and progression from lower to higher levels of design skills by design students, academics reflect on some of the limitations of the general skills development model, propose a version of the framework centred upon design, and call for more research on the transformations of designers [7]. Other studies continue to elaborate further on the behavioural and cognitive distinctions between design novices and experts during design processes and contribute to the consolidation of knowledge on those individual differences [37, 38]. Conversely, some academics shift the focus to the implications of interpersonal novice-expert interactions in design engineering activities, which implies a change in the unit of analysis from skilled individuals to heterogeneously-skilled groups [8]. Empirical evidence on the matter reveals that such interactions create new opportunities for knowledge sharing and knowledge creation [8]. In other words, evidence suggests that while being integrated, novices and experts might have the opportunity to learn from each other's experiences (knowledge sharing) and to expand the existing knowledge base (knowledge creation) that was previously available for each.

\section{Work Approach}

This case study reports on an ongoing short-term project that leverages an industryacademia collaboration, multidisciplinarity, and heterogeneous competency levels to foster the development of smart and connected devices for sustainable mobility. This section describes the work approach adopted and key developments achieved so far (four months). 


\subsection{The team}

The project team includes eight participants that differ in their roles, backgrounds, and skills. These include two final-year undergraduate design students (\#7; \#8) who are doing their internship in the project's industry partner and are directly tasked with designing the connected devices for mobility. These student interns are co-supervised by a senior design scholar (\#3) and by an engineer who works as a senior project manager in the organization (\#5). The team also includes a senior scholar and researcher (\#4) who is involved as the project manager and coordinator from the academic institution, a head of the engineering department (\#6) who is involved as a representative of the company, and two post-doctoral design researchers (\#1; \#2). Further details about the team are summarized in Table 1.

Table 1. Summary of project team characteristics.

\begin{tabular}{lcl}
\hline Institutional provenance & No. of team members & IDs \\
\hline Academia & 4 & $\# 1, \# 2, \# 3,, \# 4$ \\
Industry & 2 & $\# 5, \# 6$ \\
Academia-industry internship & 2 & $\# 7, \# 8$ \\
\hline Principal knowledge domain & No. of team members & IDs \\
\hline Design & 5 & $\# 1, \# 2, \# 3, \# 7, \# 8$ \\
Engineering & 3 & $\# 4, \# 5, \# 6$ \\
\hline Expertise in role & No. of team members & IDs \\
\hline $0-3$ years & 2 & $\# 7, \# 8$ \\
4-9 years & 3 & $\# 1, \# 5, \# 6$ \\
10 or more years & 3 & $\# 2, \# 3, \# 4$ \\
\hline
\end{tabular}

\subsection{The collaboration approach}

Due to the constraints created by the Covid-19 pandemic, all project participants had to work in a distributed manner, either from home or from their institutions' facilities, located in different geographical areas. That distributed working modality introduced challenges for the desired direct and continuous collaboration between project participants. For asynchronous sharing, the team used Microsoft Teams, in particular for preliminary information that could affect or inform the design activities. Many challenges were minimized through the use of digital technologies that allowed team members to meet online synchronously.

Two types of online sessions were held with all team members. First, an early project kick-off session was held via Zoom (digital platform), to provide an overview of the project aims, introduce the different team members and their roles, suggest the project coordination model, and to propose the design brief and the general design process that would be followed, in particular by the undergraduate design students. Second, there were three general project-progress sessions, lasting between 90 and 120 minutes. Here, the focus was for all participants to share their feedback on the evolving design concepts for the connected devices.

The team members also had frequent synchronous meetings between different participants right from the start of the project, to enable collaboration. Notably, there were 
60-minute weekly online meetings between the two student interns (\#7; \#8), their industry co-supervisor in the organization (\#5), and a researcher (\#1) to follow their progress on the design activities and provide feedback. Those sessions always took place via Zoom, although sometimes some participants (\#5, \#7; \#8;) were able to meet in person at the organization. The two undergraduate design students (\#7; \#8) also had weekly meetings with their academic supervisor (\#3). Sometimes there was the opportunity to merge the aforementioned sessions to provide an integrated industry-academia view on the progress. When appropriate, the researcher (\#2) and/or the coordinator from the academic institution (\#4) were invited to take part in those weekly sessions.

\subsection{The design process}

It was agreed at start of the project that the design work developed by the student interns would follow the four main steps of the Double Diamond framework (Fig. 1), although the micro activities involved in each stage were defined in partnership with their supervisors (\#5; \#3). The students were encouraged to learn about the company, the technologies and products of interest, and its customers, in order to understand and (re)frame the original brief during the first two stages and to design suitable concepts for connected devices for sustainable mobility during the last two steps.

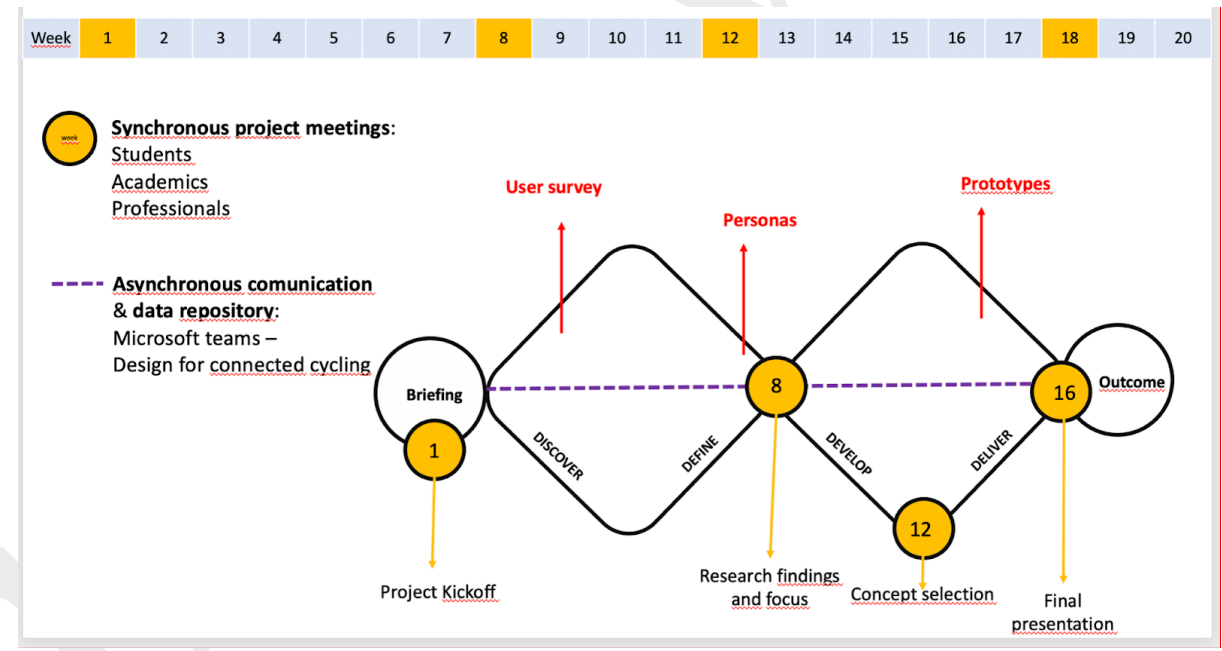

Fig. 1. Project plan including timeline, main synchronous team meetings, and sample design activities.

The following section describes three project elements of particular interest because they very clearly functioned as boundary objects in that they responded to the information needs [26] and work requirements [39] of all team members, irrespective of their individual knowledge or experience characteristics. In line with the original concept put forward by Star [25], the examples provided below were shared and shareable across different problem solving contexts. These research and design activities were 
informed by a Human-Centred Design (HCD) approach, employing recommended methods for each phase of the HCD process [40]. These were selected in light of several considerations, not least of which was their appropriateness for use while restrictions related to the Covid-19 pandemic were in place.

User Survey. For the Understand and specify context of use phase of the HCD process, a survey of cyclists' experiences was conducted through an online questionnaire. This method was deemed particularly appropriate as it would allow a diverse audience to be reached in a relatively expedient manner, which suited the project's objectives and timeframe. The questionnaire was designed for the purpose of this project and included sections on participant demographics, cycling habits, and consumer preferences related to bicycle accessories and technologies. This questionnaire was widely circulated across six countries (Portugal, Spain, France, Germany, Switzerland, Brazil) and obtained 190 responses.

Personas. Personas were used for the Specify the user and organizational requirements phase of the HCD process. Results from the aforementioned survey were used to develop four personas, as illustrated in Figure 2, following the goal-based approach proposed by Cooper [41]. Of these personas, three were male and one was female, roughly representing the gender distribution of the survey respondents $(55.8 \%$ identifying as male, $41.1 \%$ identifying as female, and the remainder preferred not to say).

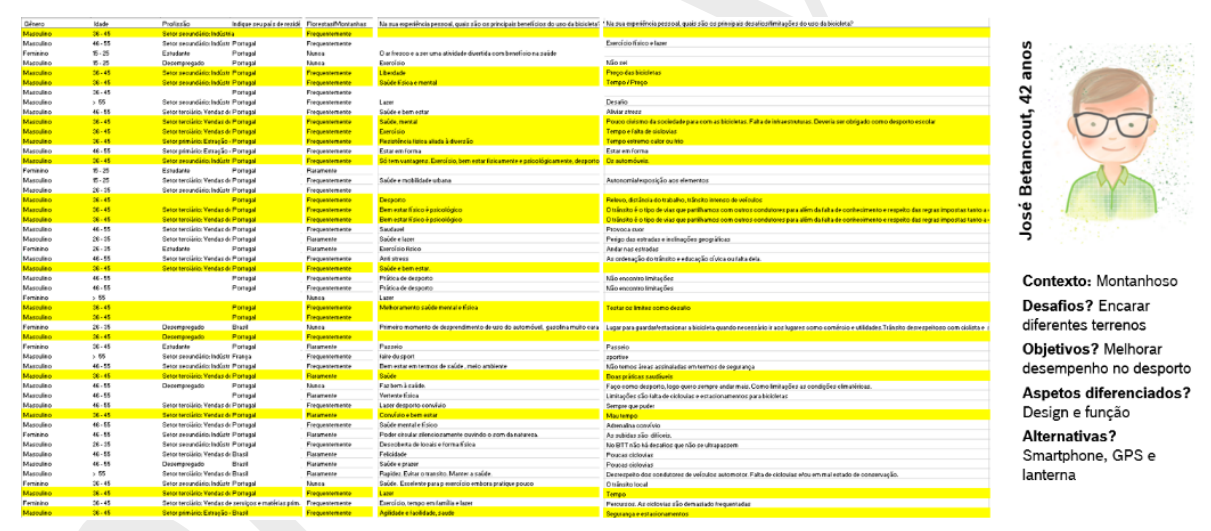

Fig. 2. Sample persona development based on user survey results.

During a team meeting (no. 8 in Fig. 1), preliminary design concepts and user requirements were discussed using the personas. Seven team members took part in this meeting, including user researchers, designers, developers, and team leaders.

Prototyping. Design concepts were developed primarily by the student interns, with input from all team members at various stages of the project. Group meetings (see Fig. 1) as well as more dedicated interactions with the student interns and their evolving concepts allowed several types of product considerations to be incorporated, including but not limited to human factors, form factors, materials, and technical feasibility. This was naturally an iterative design process, commencing with ideation and producing two final design concepts. Each concept was more or less robustly prototyped, according to its stage of development. Figure 3 shows the final prototypes for each concept. 

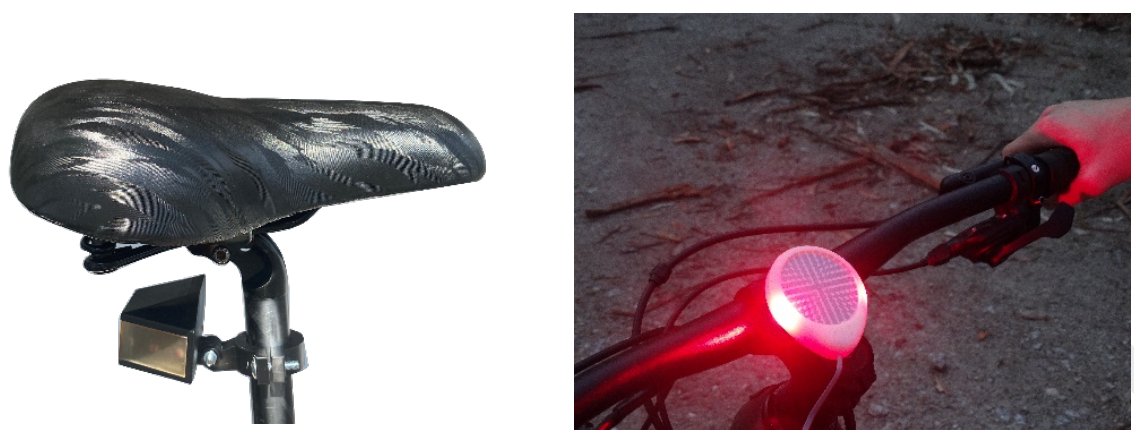

Fig. 3. Final prototypes for the two design concepts: on the left, a sensing box; on the right, an LED information display.

\section{$4 \quad$ Reflections}

Although this IAC project is still ongoing, many achievements have been made in four months. At this point, we are able to share some experiences regarding various aspects of this multidisciplinary collaboration and to reflect on our progress thus far. We discuss these here, highlighting our recommendations for similar projects in the future.

Taking the model of industry-academia closeness proposed by Wohlin [13], we position our work between levels 4 and 5 . The circumstances precipitated by the Covid19 pandemic meant that much of the work was conducted remotely, corresponding to level 4 of this model in which actors from academia work towards a solution offline. The model then suggests that a pre-packaged solution is offered to industry, which may lack the relevance or specificity to be implemented in practice. However, the collaboration approach adopted in this project meant that team members had an abundance of opportunities to feed into draft solutions and to respond to subsequent iterations, either through occasional in-person interactions (e.g., between the student interns and their supervisors) or through the regular online meetings. We argue that these were instances of working as one team (level 5 of Wohlin's model), which were facilitated by the early definition of an appropriate communication plan comprising synchronous and asynchronous channels to be used by all throughout the project. Responding to the call by Garousi et al. [9] to inform more productive industry-academia collaborations, our first recommendation is that, even if co-located teams are not feasible, the work plan should include from the outset sufficient and robust opportunities for collaboration in real time. Such synchronous moments of collaboration must be inclusive of all team members, from both industry and academia.

There was considerable knowledge diversity within the team, whose members' backgrounds included multiple branches of two main disciplines - design and engineering. In this context, elements such as the user survey, personas, and prototypes served as boundary crossing objects $[25,26]$, enabling all team members to convene around shared knowledge within the scope of the project. This is in line with [28, 29]. More interesting, though, was the role played by boundary crossing individuals [27] within the project. The more consistent boundary crossing was undertaken by the student 
interns, who were closely supervised by a design scholar and by an engineer within the partner industry and who therefore necessarily operated between academia and industry, as well as between the disciplinary boundaries they comprised. Similarly, the two post-doc researchers also operated as boundary spanning individuals, as their work connected them to all information areas within the project (ranging from the student interns to more senior team members) and therefore uniquely placed to disseminate new information and ideas amongst the rest of the team [27]. This lends evidence to our second recommendation, which is to formalize the requirement for boundary crossing roles at the start of the project and to be explicit about who will play those roles. This requires having appropriate skills to not limit their work to their knowledge domain.

Concerning individual competency development through different levels, this project revealed various findings that might be relevant for future initiatives. This project supports the idea by Dorst and Reymen [7] that design students can reveal different levels of individual competency in relation to a single domain (in this case, design) or project since the types of activities conducted by each student intern were very diverse, and they were not equally skilled in those activities. Similar observations were made about the academics and professionals with different backgrounds who were involved in the project. That means that the characterization of individuals in a single level of competency might be ineffective at times, since individual team members might be novices in some activities while simultaneously experts in other activities that are associated with the same overarching domain (researcher, designer, engineer, etc.). Based on that observation, we recommend an early focus on obtaining a more granular understanding of individual skills for specific tasks, as opposed to inferring expertise from an overall domain, to expedite team building and project coordination activities (e.g., division of labour).

The project further revealed that the combination of a learning-by-doing approach (in which opportunities were created for team members with different roles and responsibilities to apply their skills in project activities) and a more structured instructional approach (joint expert feedback sessions) became complementary in supporting the individual competency development. Notably, while the first enabled participants to execute tasks and develop tacit knowledge that is not easily articulated or communicated, the second provided access to more formalized knowledge and created some room for reflection upon the doings. With that in mind, we suggest that future projects should not only include opportunities for learning-by-doing, but also more structured learning initiatives to allow individuals to uplift their skills.

Moreover, our findings support the argument that novice-expert interactions in design engineering activities can contribute to creating new (specific) knowledge [8]. In this case, the interactions proved to be essential for creating new knowledge (concepts, ideas, models) concerning sustainable mobility and connected devices, which over time have become shared across the team members involved in the project. That suggests that team members in general also gradually evolved to more skilled professionals in designing connected devices for mobility due to the lived experiences accumulated throughout this project. Interestingly, it was apparent during the project that the new shared knowledge on cycling devices was facilitating the communication between team members. In light of these observations, we recommend that future endeavours should 
not only take into consideration individual skill development, but also the formation of new knowledge and skills shared at the group level as they might work as intangible boundary objects that enable a better understanding between individuals [28].

Finally, in this section we have highlighted the main findings and recommendations that we believe might have the potential to inform comparable projects in the future. Still, we are aware that these observations are based on a single and ongoing case, and therefore they should be taken mindfully. Further studies on design projects that lie at the intersection between industry-academia collaborations, knowledge diverse and competence-heterogeneous individuals should be pursued to validate or challenge the main points made in this article.

\section{Conclusions}

This paper reports on an ongoing short-term collaborative project, which aims to develop innovative concepts for smart and connected cycling. This project brings together a heterogeneous team in terms of three core factors that are known to enhance innovation potential: (i) industry-academia collaboration, (ii) knowledge diversity, and (iii) different levels of experience and expertise. Effectively assembling such a diverse team to work together towards a common goal can incur known challenges, which here involved additional limitations related to the Covid-19 pandemic. In this case study, we describe the project progress focusing specifically on the initial planning, team collaboration, and how the design activities are being implemented throughout the project. We conclude by reflecting on the project outcomes so far, framed within relevant literature on pathways to industry-academia collaboration, integrating knowledge diversity, boundary negotiations, individual competency development, and knowledge implications led by interpersonal novice-expert interactions. In doing so, we offer main empirical findings and five recommendations for similar collaborative projects in the future. We believe this paper makes a timely contribution to current discussions around multiactor design projects in different cross-boundary contexts.

\section{Aknowledgements}

This work is supported by European Structural and Investment Funds in the FEDER component, through the Operational Competitiveness and Internationalization Programme (COMPETE 2020) [Project no 039334; Funding Reference: POCI-01-0247FEDER-039334]. This work has additional financial support from Project Lab2PT Landscapes, Heritage and Territory laboratory - AUR/04509, with financial support from FCT/MCTES through national funds (PIDDAC) and co-financing from the European Regional Development Fund (FEDER) POCI-01-0145-FEDER-007528, in line with the new partnership agreement PT2020 through COMPETE 2020 - Compet- itiveness and Internationalization Operational Program (POCI). 


\section{References}

1. Rittel, H.W.J., Webber, M.M.: Dilemmas in a general theory of planning. Policy Sci. 4, 155169 (1973). https://doi.org/10.1007/BF01405730.

2. Chesbrough, H.W.: Open Innovation: The new imperative for creating and profiting from technology. Harvard Business Press (2003).

3. Fey, C.F., Birkinshaw, J.: External sources of knowledge, governance mode, and R\&D performance. Journal of Management. 31, 597-621 (2005). https://doi.org/10.1177/0149206304272346.

4. Baer, J.: The importance of domain-specific expertise in creativity. Roeper Review. 37, 165178 (2015). https://doi.org/10.1080/02783193.2015.1047480.

5. Wowk, K., McKinney, L., Muller-Karger, F., Moll, R., Avery, S., Escobar-Briones, E., Yoskowitz, D., McLaughlin, R.: Evolving academic culture to meet societal needs. Palgrave Communications. 3, 1-7 (2017). https://doi.org/10.1057/s41599-017-0040-1.

6. Dreyfus, S.E., Dreyfus, H.L.: A five-stage model of the mental activities involved in directed skill acquisition. California Univ. Berkeley Operations Research Center (1980).

7. Dorst, K., Reymen, I.: Levels of expertise in design education. In: Proceedings of the 2 nd International Engineering and Product Design Education Conference, 2-3 September 2004, Delft. pp. 159-166. Delft University of Technology (2004).

8. Deken, F., Kleinsmann, M., Aurisicchio, M., Lauche, K., Bracewell, R.: Tapping into past design experiences: Knowledge sharing and creation during novice-expert design consultations. Res Eng Design. 23, 203-218 (2012). https://doi.org/10.1007/s00163-011-0123-8.

9. Garousi, V., Pfahl, D., Fernandes, J.M., Felderer, M., Mäntylä, M.V., Shepherd, D., Arcuri, A., Coşkunçay, A., Tekinerdogan, B.: Characterizing industry-academia collaborations in software engineering: evidence from 101 projects. Empir Software Eng. 24, 2540-2602 (2019). https://doi.org/10.1007/s10664-019-09711-y.

10. García-González, A., Ramírez-Montoya, M.-S.: Systematic mapping of scientific production on Open Innovation (2015-2018): Opportunities for sustainable training environments. Sustainability. 11, 1781 (2019). https://doi.org/10.3390/su11061781.

11. Buchanan, R.: Wicked problems in Design Thinking. Design Issues. 8, 5-21 (1992). https://doi.org/10.2307/1511637.

12. Coyne, R.: Wicked problems revisited. Design Studies. 26, 5-17 (2005). https://doi.org/10.1016/j.destud.2004.06.005.

13. Wohlin, C.: Software engineering research under the lamppost. ICSOFT 2013 - 8th International Joint Conference on Software Technologies., Reykjavík, Iceland (2013).

14. Garousi, V., Petersen, K., Ozkan, B.: Challenges and best practices in industry-academia collaborations in software engineering: A systematic literature review. Information and Software Technology. 79, 106-127 (2016). https://doi.org/10.1016/j.infsof.2016.07.006.

15. Misirli, A.T., Erdogmus, H., Juristo, N., Dieste, O.: Topic selection in industry experiments. In: Proceedings of the 2nd International Workshop on Conducting Empirical Studies in Industry. pp. 25-30. Association for Computing Machinery, New York, NY, USA (2014). https://doi.org/10.1145/2593690.2593691.

16. Runeson, P.: It takes two to tango - An experience report on industry-academia collaboration. In: Verification and Validation 2012 IEEE Fifth International Conference on Software Testing. pp. 872-877 (2012). https://doi.org/10.1109/ICST.2012.190. 
17. Sandberg, A., Pareto, L., Arts, T.: Agile collaborative research: Action principles for Industry-Academia Collaboration. IEEE Software. 28, 74-83 (2011). https://doi.org/10.1109/MS.2011.49.

18. Eldh, S.: Some researcher considerations when conducting empirical studies in industry. In: 2013 1st International Workshop on Conducting Empirical Studies in Industry (CESI). pp. 69-70 (2013). https://doi.org/10.1109/CESI.2013.6618476.

19. Kaindl, H., Brinkkemper, S., Bubenko Jr, J.A., Farbey, B., Greenspan, S.J., Heitmeyer*, C.L., Leite†, J.C.S. do P., Mead, N.R., Mylopoulos, J., Siddiqi, J.: Requirements engineering and technology transfer: Obstacles, incentives and improvement agenda. Requirements Eng. 7, 113-123 (2002). https://doi.org/10.1007/s007660200008.

20. Morris, P., Masera, M., Wilikens, M.: Requirements engineering and industrial uptake. In: Proceedings of IEEE International Symposium on Requirements Engineering: RE '98. pp. 130-137 (1998). https://doi.org/10.1109/ICRE.1998.667818.

21. Parjanen, S.: Experiencing creativity in the organization: From individual creativity to collective creativity. Interdisciplinary Journal of Information, Knowledge, and Management. 7, 109-128 (2012). https://doi.org/10.28945/1580.

22. Moirano, R., Sánchez, M.A., Štěpánek, L.: Creative interdisciplinary collaboration: A systematic literature review. Thinking Skills and Creativity. 35, 100626 (2020). https://doi.org/10.1016/j.tsc.2019.100626.

23. Parjanen, S., Hyypiä, M.: Innotin game supporting collective creativity in innovation activities. Journal of Business Research. 96, 26-34 (2019). https://doi.org/10.1016/j.jbusres.2018.10.056.

24. Carlile, P.R.: A pragmatic view of knowledge and boundaries: Boundary objects in new product development. Organization Science. 13, 442-455 (2002). https://doi.org/10.1287/orsc.13.4.442.2953.

25. Star, S.L.: The Structure of ill-structured solutions: Boundary objects and heterogeneous distributed problem solving. In: Gasser, L. and Huhns, M.N. (eds.) Distributed Artificial Intelligence. pp. 37-54. Morgan Kaufmann, San Francisco (CA) (1989). https://doi.org/10.1016/B978-1-55860-092-8.50006-X.

26. Star, S.L., Griesemer, J.R.: Institutional ecology, "translations" and boundary objects: Amateurs and professionals in Berkeley's Museum of Vertebrate Zoology, 1907-39. Soc Stud Sci. 19, 387-420 (1989). https://doi.org/10.1177/030631289019003001.

27. Tushman, M.L., Scanlan, T.J.: Boundary spanning individuals: Their role in information transfer and their antecedents. AMJ. 24, 289-305 (1981). https://doi.org/10.5465/255842.

28. Koskinen, K.U.: Metaphoric boundary objects as co-ordinating mechanisms in the knowledge sharing of innovation processes. European Journal of Innovation Management. 8, 323-335 (2005). https://doi.org/10.1108/14601060510610180.

29. Tharchen, T., Garud, R., Henn, R.L.: Design as an interactive boundary object. Journal of Organization Design. 9, 21 (2020). https://doi.org/10.1186/s41469-020-00085-w.

30. Dreyfus, S.E.: Formal models vs. human situational understanding: Inherent limitations on the modeling of business expertise. Office Technology and People. 1, 133-165 (1982). https://doi.org/10.1108/eb022609.

31. Dreyfus, H.L., Dreyfus, S.E., Athanasiou, T.: Mind over machine: The power of human intuition and expertise in the era of the computer. The Free Press, USA (1986). 
32. Benner, P.: Using the Dreyfus Model of skill acquisition to describe and interpret skill acquisition and clinical judgment in nursing practice and education. Bulletin of Science, Technology \& Society. 24, 188-199 (2004). https://doi.org/10.1177/0270467604265061.

33. Lyon, L.J.: Development of teaching expertise viewed through the Dreyfus Model of skill acquisition. Journal of the Scholarship of Teaching and Learning. 15, 88-105 (2015).

34. Persky, A.M., Robinson, J.D.: Moving from novice to expertise and its implications for instruction. AJPE. 81, (2017). https://doi.org/10.5688/ajpe6065.

35. Lawson, B.: Schemata, gambits and precedent: Some factors in design expertise. Design Studies. 25, 443-457 (2004). https://doi.org/10.1016/j.destud.2004.05.001.

36. Cross, N.: Expertise in design: An overview. Design Studies. 25, 427-441 (2004). https://doi.org/10.1016/j.destud.2004.06.002.

37. Kavakli, M., Gero, J.S.: The structure of concurrent cognitive actions: A case study on novice and expert designers. Design Studies. 23, 25-40 (2002). https://doi.org/10.1016/S0142694X(01)00021-7.

38. Jagtap, S.: Shaping products: Differences between expert and novice industrial designers. Presented at the (2018). https://doi.org/10.21278/IDC.2018.0159.

39. Star, S.L.: This is not a boundary object: Reflections on the origin of a concept. Science, Technology, \& Human Values. 35, 601-617 (2010). https://doi.org/10.1177/0162243910377624.

40. Maguire, M.: Methods to support human-centred design. International Journal of HumanComputer Studies. 55, 587-634 (2001). https://doi.org/10.1006/ijhc.2001.0503.

41. Cooper, A.: The inmates are running the asylum. Sams (1999). 